\title{
Zubiri y la filosofía de la praxis en Iberoamérica
}

Zubiri and the philosophy of praxis in Ibero-America

\author{
Óscar Barroso Fernández
}

Universidad de Granada.

\author{
ATEÍSMO, CREENCIA Y SENTIDO. HOMENAJE A JUAN ANTONIO ESTRADA \\ MONOGRÁFICO COORDINADO POR REMEDIOS ÁVILA Y MIGUEL MORENO
}

\begin{abstract}
RESUMEN
Este trabajo pretende explicar cómo es posible que una filosofía de corte metafísico como la de Zubiri haya ejercido una influencia tan significativa en la filosofía de la praxis iberoamericana. Atenderé especialmente a su momento más sobresaliente: la filosofía de la realidad histórica de Ignacio Ellacuría. Respecto a este, existe la tentación de considerar que la interpretación que hace de Zubiri está desfasada. Esta tentación se explica por la tendencia a leer la obra de Zubiri de forma evolutiva y en perspectiva fenomenológica, considerando que "Inteligencia sentiente" (1983) supera a "Sobre la esencia" (1962); obra sobre la que, precisamente, Ellacuría propone su interpretación de Zubiri. Por nuestra parte, defenderemos que una filosofía de la praxis de raigambre zubiriana no puede desatender a lo metafísico en pos de lo fenomenológico.
\end{abstract}

\section{ABSTRACT}

This paper aims to explain the reasons for the significant influence of Zubiri's metaphysical philosophy on Ibero-American philosophy of praxis. In order to address this subject, I focus on the most preeminent figure of the latter: Ignacio Ellacuria's philosophy of historical reality. There is a temptation to think that his interpretation of Zubiri's philosophy is outdated. This could be explained by the tendency to read Zubiri's work from an evolutionary and phenomenological perspective. Therefore "Inteligencia sentiente" (1984) would overcome "Sobre la esencia" (1962), the work on which Ellacuría proposes his interpretation. Against that, I argue that a philosophy of praxis with zubirian roots can not ignore metaphysics in favor of the phenomenological standpoint.

PALABRAS CLAVE

Zubiri | Ellacuría | filosofía | praxis | liberación | historia

KEYWORDS

Zubiri | Ellacuría | philosophy | praxis | liberation | history

\section{Introducción}

En el presente trabajo voy a analizar la interpretación de Zubiri desde la filosofía de la praxis en el horizonte de la filosofía de la liberación. Me referiré de forma especial al proyecto de una filosofía de la realidad histórica desarrollado por Ignacio Ellacuría en el contexto de la Universidad Centroamericana.

Con el objetivo de demarcar adecuadamente la lectura que Ellacuría hace de Zubiri, la contrapondré a la praxeología de Antonio González (continuador del magisterio de Ellacuría en la UCA), intentado mostrar cómo estas dos filosofías de la praxis parte de dos interpretaciones diferentes de Zubiri, respectivamente, metafísica y fenomenológica. Argumentaré, además, en favor de las ventajas del planteamiento de Ellacuría sobre el de González, lo que me obligará a romper el orden natural de exposición. Con esta decisión metodológica pretendo también dejar atrás un prejuicio evolutivo respecto de la filosofía de Zubiri: la idea de que ha de interpretarse desde su última obra, Inteligencia sentiente (1980-1983), horizonte en el que se sitúa González, restando valor a Sobre la esencia (1962), obra a la que Ellacuría dedicó su tesis doctoral y que constituyó su horizonte interpretativo (Güell 2013: 748-750).

Cabe la pregunta sobre por qué tratar esta temática en un número monográfico en homenaje al profesor Juan Antonio Estrada. La conexión debe resultar clara con solo mencionar la estrecha relación del maestro con la teología de la liberación y su magisterio en la Universidad Centroamericana, sostenido durante años en los meses estivales, es decir, cuando las aulas de la Universidad de Granada estaban cerradas.

Para quien conozca la obra de Estrada, salta a la vista que su inmersión en la teología de la liberación toma como anclaje la Teoría Crítica, especialmente en las figuras de Horkheimer y Habermas (Estrada 
1990 y 2004). Pero también analizó en un artículo de 1998 la influencia de Zubiri en la teología de la liberación. En él partía de la sorpresa que producía que una filosofía como la de Zubiri influyera en la teología de la liberación. Zubiri era un metafísico, despreocupado, en principio, por la filosofía de la praxis, y, por lo tanto, en las antípodas de un intelectual como Ellacuría, que llegó al límite de asumir el sacrificio de la propia vida en la lucha por la justicia (Hogue 2018).

¿Qué había en Zubiri que pudiera resultar atractivo para la teología de la liberación? Estrada observa que para esta "la iniciativa salvífica" de Dios apela "a la mediación humana", lo que implica una vuelta de la religión "a la historia y a la praxis" (Estrada 1998: 286). Es decir, la teología de la liberación no permanece a la espera de una salvación trascendente sino que considera que debe buscarse en este mundo, aunque más como un ideal regulativo que como una proyección teleológica y cerrada sobre sí misma:

"El hombre construye el reinado de Dios en el aquí y ahora de la historia, la salvación acaece intramundanamente y la intervención última divina es la que permite mantener abierta la historia (contra toda pretensión de absolutizar las utopías y proyectos intrahistóricos), así como el carácter asintótico y referencial del reino de Dios como meta de la historia, a la que hay que tender y anticipar, transformando la realidad, pero que, en última instancia, es inalcanzable para el hombre" (Estrada 1998: 286).

Por puesto, si se trata de salvar al ser humano en este mundo, dicha salvación no puede ser meramente espiritual, sino la del hombre de carne y hueso, que sufre y muere. Si lo mejor del cristianismo estuvo en su sensibilidad hacia el pobre en particular y las víctimas en general, ahora el compromiso con ellos va más allá del consuelo trascendente: el objetivo es liberarlas en la historia. Como escribe Don Schweitzer (2018), se trata de "trabajar para bajar a los crucificados de la cruz".

Precisamente, en este contexto resultará fundamental la comprensión zubiriana del fenómeno religioso desde su dimensión religativa: desde la implantación del hombre en la realidad, constituida como poder y fuente de posibilidades para su realización histórica tanto desde el punto de vista individual como social. Pero este Zubiri teólogo está montado sobre el metafísico; el filósofo de la realidad que hace de la metafísica un saber esencialmente intramundano y fundamental para la comprensión de lo social y lo histórico. Desde aquí, escribe Estada, "el problema no es recuperar el sentido de la fe para el hombre moderno, sino liberar la realidad vigente de la miseria opresora" (Estrada 1998: 292). Porque, con Zubiri, la inteligencia no consiste fundamentalmente en comprensión de sentido, sino "en afrontar la realidad en cuanto tal, en captarla, enfrentando al hombre con su contexto" (Estrada 1998: 293). Y esto es lo que permite que un filósofo eminentemente metafísico pueda ser a la vez apropiado desde una filosofía de la praxis.

Este es el trasfondo de la lectura de Estrada, y ella orientó mi propia comprensión del fenómeno. Aquí, el verbo en pretérito tiene un recorrido de más de 20 años, ya que el texto del maestro fue determinante en la construcción de mi Zubiri. Efectivamente el artículo llegó a mis manos, como obsequio del propio Juan Antonio en el mismo año en que comenzaba mi tesis doctoral. Su influencia parece obvia con solo mencionar el título de mi tesis, Hombre, verdad y moral en la antropología de Xavier Zubiri. Los fundamentos de la filosofía de la praxis (2002), y de mi libro Verdad y acción. Para pensar la praxis desde la inteligencia sentiente zubiriana (2002). Las líneas que siguen son por tanto el decantado de algo que comenzó a fraguarse en aquel contexto. Sirvan como modesto reconocimiento del discípulo al maestro.

\section{La filosofía zubiriana como filosofía de la praxis}

Han sido diversos los intentos de desarrollar una filosofía de la praxis con raíces en el pensamiento de Zubiri. En parte, éstos venían ya profetizados por José Luis López Aranguren a finales de los años cincuenta, cuando descubrió que Zubiri no solo recuperaba el sentido del bíos theoretikós aristotélico, sino que iba más allá al introducir en su estructura la poíesis desde la constatación de que "el saber implica el 'penetrar', 'registrar' e 'intervenir', y hay por tanto, una unidad intrínseca entre saber y modificar" (López Aranguren 1958: 55).

Es obvio que son muchas las tendencias filosóficas que plantean esto en nuestro siglo, pero muy pocas 
las que lo apoyan sobre una filosofía de corte metafísico, cuyo núcleo es la ineludible instalación del ser humano en la realidad. Aquí reside el atractivo fundamental del planteamiento zubiriano.

La filosofía de Zubiri nace de la necesidad de superar la crisis nihilista, vivida en su juventud en primera persona (Corominas y Vincens 2006: 111-131), volviendo a radicar al ser humano en la verdad, en el fundamento. Desde la fundamentación del ámbito de la realidad, inteligencia, sentimiento y voluntad pueden volver a encontrar su arraigo en el mundo. Por ello, en Zubiri lo metafísico no coincide con lo especulativo, permitiento, más bien al contrario, la apertura radical a la praxis. Estamos ante una filosofía de la actualidad de la realidad en el hombre y del hombre en la realidad; comprometida con la recuperación de la experiencia originaria de apertura del ser humano a la realidad; dejando atrás al sujeto soberano de la modernidad, que al situarse sobre la realidad, al desprenderse de su radical arraigo y dar prioridad a la mediación racional, ha arribado a una apremiante crisis nihilista. Frente a esta crisis, Zubiri busca recuperar el arraigo y la confianza en la realidad. No es extraño, entonces, que termine su trilogía de la siguiente forma:

"Inteligir y sentir no solo no se oponen sino que, pese a su esencial irreductibilidad, constituyen una sola estructura, una misma estructura que según por donde se mire debe llamarse inteligencia sentiente o sentir intelectivo. Gracias a ello, el hombre queda inamisiblemente retenido en y por la realidad: queda en ella sabiendo de ella. Sabiendo ¿qué? Algo, muy poco, de lo que es real. Pero, sin embargo, retenido constitutivamente en la realidad. ¿Cómo? Es el gran problema humano: saber estar en la realidad" (Zubiri 1983: 351-352).

Es por ello normal que no solo interpretes ideológicamente próximos al marxismo, como el propio Ellacuría, sino también otros en principio distantes, como Diego Gracia, intentaran conectar -en un momento histórico en el que el marxismo inundaba la actividad académica en nuestro país-, la filosofía de Zubiri con intuiciones fundamentales de Marx (1).

¿En qué sentido se puede decir que la filosofía de Zubiri es una filosofía de la praxis? Pues fundamentalmente en el apuntado por Aranguren y que refleja la unidad de toda acción humana en la expresión "saber estar en la realidad".

Ciertamente este no es el sentido que el marxismo ha dado a la filosofía de la praxis. Antonio González (1997: 13) prefiere hablar de "praxeología" para evitar las confusiones (․).

López Aranguren (1958: 56) escribe lo siguiente en relación a la unidad de theoría, práxis y poíesis en Zubiri:

"podría tener tal vez razón Marx en su crítica a los filósofos -'los filósofos no han hecho más que interpretar el mundo, pero la cuestión es cambiarlo'-, referida a tales o cuales filósofos, pero no, de ningún modo, si pretende alcanzar a la actitud filosófica -filosofía en su pleno sentido, filosofía como ética también- en cuanto tal. La filosofía, en su vertiente ética, realiza la síntesis de conocimiento y existencia, tiende constitutivamente a la realización".

Esta afirmación hace preciso delimitar respecto al marxismo lo que aquí entendemos por filosofía de la praxis.

Fue Antonio Gramsci el que introdujo la expresión en el marxismo. Él la entendía como una entrada en conciencia del actuar: "El hombre-masa activo opera prácticamente, pero no tiene una clara conciencia teórica de su obrar que, sin embargo, es un conocer el mundo en tanto que lo transforma" (Gramsci 1953: 24). Ocurría incluso que la concepción del mundo del hombre-masa era contradictoria con su práctica. Y, precisamente, la filosofía de la praxis pretendía superar esto a través de un proceso dialéctico entre los intelectuales y la masa que condujera a "una concepción de lo real que ha superado el sentido común y se ha hecho crítica" (Gramsci 1953: 24). En este proceso dialéctico debía hacerse presente la concepción del mundo contenida en el obrar práctico de los hombres, y, al mismo tiempo, la filosofía debía salir del círculo de los "iniciados" e impregnar a toda la sociedad:

"La filosofía de una época no es la filosofía de uno u otro filósofo, de uno u otro grupo de intelectuales, de uno u otro sector de las masas populares: es una combinación de todos estos elementos que culmina en una determinada dirección y en este culminar se convierte en norma de acción colectiva, es decir, en 'historia' concreta y completa (integral)" (Gramsci 1953: 40). 
La filosofía de la praxis se configura como una concepción del mundo que lucha por ser difundida para transformar la mentalidad popular y, por lo tanto, como el intento de igualación de filosofía y política, de pensamiento y acción.

Las diferencias entre el planteamiento de Gramsci y el de Zubiri son claras. En Zubiri no se debe entender la filosofía de la praxis como la dialéctica intelectuales-masa que conduciría a una filosofía del actuar -una concepción del mundo coherente con una práctica social determinada-. Tampoco como la igualación de filosofía y política. Se trata en realidad de algo previo: la filosofía que se deriva del descubrimiento de la intrínseca unidad del conocer, del comportamiento moral y del actuar sobre el medio.

Ello significa que la filosofía de la praxis requiere como paso previo la elaboración de una antropología. Pero entonces, aún las grandes diferencias, es posible el complemento recíproco de las filosofías de Gramsci y Zubiri. Máxime si tenemos en cuenta que el primero entendió que la pregunta principal de la filosofía es "qué es el hombre"; lo que equivale a preguntar "¿qué puede llegar a ser el hombre?; es decir si el hombre puede dominar el propio destino, puede 'hacerse', puede crearse una vida" (Gramsci 1953: 48). Ello implica que la pregunta debe englobar de forma esencial las dimensiones social e histórica del ser humano (․ㅡ). En este sentido, la sintonía con Zubiri es clara. La consideración de una antropología tal, tanto en uno como en otro, permite replantear nociones como la de "progreso", liberándola de su aspecto mecanicista y cientista, y entendiéndola como el esfuerzo social e histórico a través de la libertad -apropiación de posibilidades- por dominar la naturaleza y el azar buscando el mejoramiento del hombre, de su saber estar en la realidad. La filosofía zubiriana no supone la postulación de una ética concreta, pero sí una antropología en la que pueden engarzarse coherentemente todos estos elementos. En este sentido, la filosofía de la praxis se constituye como exponente de aquella tradición humanista que se basa en una apuesta y confianza en el ser humano, en su capacidad de transformación del mundo. Apuesta y confianza puesta hoy, no sin razones, en tela de juicio.

\section{Las interpretaciones fenomenológica y metafísica de la filosofía de Zubiri}

Se puede hablar de dos interpretaciones relacionadas con el transcurrir temporal del pensamiento de Zubiri y, más específicamente, con sus decisiones metodológicas. Así, entre los especialistas en Zubiri, ha sido habitual pensar que en su obra confluyen dos metodologías que dan lugar a dos esferas de problemas filosóficos: la "metafísica" y la "filosofía primera" (Gracia 1986: 101-117, Pintor 1994, Conill 1988: 232). Mientras que la primera refiere al resultado de esbozos racionales, una filosofía explicativa, la segunda parte de un análisis radical, fenomenológico (4).), de lo dado directa e inmediatamente a la aprehensión humana, una filosofía descriptiva.

Recordemos brevemente que en Inteligencia sentiente Zubiri defendió que la inteligencia humana está internamente modulada por tres momentos: aprehensión de realidad, logos y razón. El logos describe el campo de realidad, constituido por las cosas tal como son dadas directa e inmediatamente a la aprehensión; mientras que la razón obedece al intento de ir del campo al mundo, de la experiencia intraaprehensiva a su explicación allende la misma. Pues bien, mientras que la filosofía primera intenta atenerse a lo dado en el campo, la metafísica buscaría la explicación mundanal de lo campal, su fundamento. Pero lo campal tiene también un papel esencial en el aparato cognoscitivo; ya que en la realidad campal -constituida en sistema de referencia, canon y principio- los esbozos racionales encuentran su apoyo y fundamento (므). Por ello Antonio Pintor y Diego Gracia llaman a la filosofía zubiriana, en cuanto descriptiva, "filosofía primera". La tarea fundamental y primordial de la filosofía será el análisis fenomenológico, campal, de lo dado en la aprehensión primordial de realidad, porque los éxitos de nuestros esbozos racionales dependen de una buena conceptualización campal de esta realidad.

Es preciso decir que Zubiri no solía utilizar estos conceptos para referirse a los distintos métodos con los que abordaba la tarea filosófica. Él simplemente hablaba de descripción de hechos y explicación. Además, solo utilizó tal distinción en Inteligencia sentiente, donde lo que no es mero análisis "noológico" queda relegado a apéndices explicativos (ㅁ). El hecho de que en esta obra considere que la noología constituye el análisis descriptivo, permite utilizar este término como sinónimo de filosofía primera; siempre y cuando se aclare que ello no implica que solo se puede hacer un análisis descriptivo del acto de intelección, con lo que todo lo que rebasase este ámbito estaría más allá de la descripción de hechos. 
Ya que, en primer lugar, también se puede hacer un análisis descriptivo de otros momentos de la realidad humana como el sentimiento, la voluntad o el carácter personal. En segundo lugar, no solo se pueden analizar fenomenológicamente los actos humanos, sino también la realidad actualizada en esos actos, $l o$ dado a la intelección misma. Precisamente, Antonio González (1997: 37) parece olvidar esto último al limitar el análisis noológico a los actos de intelección dejando fuera de lugar la realidad actualizada.

Pero no solo aparecen problemas a la hora de denominar el filosofar descriptivo en Zubiri (1980: 113-122), sino que también el concepto de "metafísica" aplicado a la explicación es problemático en tanto que este consideró en su trilogía que la metafísica era el análisis de la estructura trascendental de la aprehensión y, por tanto, caía dentro del objeto de la noología.

Estas disquisiciones metodológicas no han tenido otra intención que la de aclarar en qué consisten las dos tendencias a las que nos referíamos al principio de este apartado: una ligada más al carácter metafísico de su obra; la otra con la mirada puesta fundamentalmente en la filosofía primera.

La interpretación metafísica ha considerado especialmente la filosofía de la historia zubiriana. Esta es la línea de influencia fundamental y directa en Ellacuría. González se sitúa, en cambio, en la interpretación fenomenológica, desde la convicción de que es posible extraer del análisis fenomenológico de los actos humanos elementos altamente pertinentes para fundamentar nuestra acción. Los análisis derivados de la praxeología servirán como sistema de referencia, principio y canon de nuestras concretas construcciones racionales para saber estar en la realidad, y, en general, como elementos relevantes para orientar la acción humana.

El problema fundamental que detectamos en la interpretación fenomenológica es su incompatibilidad con algunos supuestos básicos del pensamiento de Zubiri. Concretamente, la tendencia a considerar la praxeología como filosofía del acto de aprehensión (González 1997: 188) implica el retorno a algo contra lo que Zubiri lucha enérgicamente: la separación de noesis y noema. Para Zubiri, no es posible hacer referencia al acto intelectivo sin incluir la propia formalidad de realidad. Ello se debe a la co-implicación de la "actualidad" de la realidad en la inteligencia y la de la inteligencia en la realidad.

En lo que sigue nos centraremos en la interpretación metafísica. En todo caso, la referencia aquí crítica y breve a la interpretación fenomenológica, no debe entenderse como un rechazo de esta perspectiva, que aun cuando se separe de Zubiri, manifiesta una línea de investigación coherente y rigurosa.

\section{Una filosofía de la historia con raigambre zubiriana}

Un elemento destaca en la filosofía de la historia desarrollada a partir del planteamiento zubiriano: el compromiso que el ser humano adquiere con el respeto de la realidad en general y la realidad humana en particular. Todas nuestras ideas, ideales y proyectos engarzan en la realidad, a la que, por tanto, estamos obligados. Como vio Adela Cortina (1996: 57):

"Frente a los intentos idealistas, mostrar la inserción del hombre en la realidad, el hecho de que esté obligado a ella, es -creo yo- el interés rector de la propuesta zubiriana: a la constitución del hombre pertenece estar ya siempre implantado en la realidad, religado a ella y a ella obligado, porque con la realidad tenemos que habérnoslas, de ella hemos de hacernos cargo y nos resulta ineludible justificar la elección de posibilidades de la que es fuente".

La filosofía zubiriana emprende la tarea de recuperar la esencial vinculación entre el agente moral y el mundo (la realidad, tanto natural como personal); es el proyecto de un realismo moral. Por su inteligencia sentiente el ser humano queda "retenido en y por la realidad" (Zubiri 1983: 351-352). Por ello no puede pretender proyectos como mera idealidad, sino que su gran problema es, una vez se sabe atenido a lo real, saber estar en la realidad. El ser humano se hace en la realidad dada, en la familiaridad en su haber experiencial con las cosas, en el que recrea la realidad a partir de lo irreal. El proyecto, lo irreal, es irrealidad de lo real y está orientado siempre a la recuperación de lo real por realización experiencial.

¿Qué sentido tiene, entonces, una ética despreocupada de "las resistencias que obstaculizan y de los cauces que hacen factible que el bien acontezca en las situaciones concretas?" (Hortal 1996: 77). La escisión entre lo factible y lo deseable no es solo ilusoria, sino también irresponsable. Pero este es el resultado del idealismo moral, constituyéndose en una moral futurista irresponsable tanto con la 
facticidad como con las consecuencias de nuestro comportamiento moral. A esto es a lo que se opone el realismo zubiriano.

La filosofía zubiriana exige una apertura al futuro, pero solo como una praxis concreta sobre el presente y sabiéndose asentada en un proceso histórico que la posibilita. En este sentido se pronuncia Augusto Hortal (1996: 78):

"El realismo en principio acentúa no solo la realidad que siempre es, sino también la que ha venido a ser desde el pasado, y también (al menos eso proponemos aquí) la realidad que esperamos que alguna vez llegue a ser en el futuro mediante nuestras actuaciones éticas. En cambio, el idealismo vive de la apertura al futuro, se interesa más por las posibilidades y opciones abiertas que por las realizaciones elegidas o las realidades asumidas".

Por su parte, Jordi Corominas (1993: 61) observa que, si "en su sentido más radical la justicia consiste en ajustarse a la realidad", entonces los ideales y proyectos que no se ajusten resultarán injustos: "es inmoral todo proyecto imposible, que no tome en cuenta las posibilidades reales de las personas". Y es en la experiencia donde se detecta qué elementos se presentan a la historia más humanizadores. Por ello nuestra voluntad no es meramente inventiva, sino que se asienta sobre las posibilidades que la realidad, en la experiencia, nos ofrece; tiene unos condicionamientos materiales, reales y no puede ser considerada producto de nuestra pura interioridad. La construcción de nuestros esbozos morales exige una mediación continua con estos condicionamientos con el fin de liberarlos de la irresponsabilidad ética que parece haber caracterizado a nuestra llustración (7). Solo desde la consciencia de estos condicionamientos, cada sociedad puede abrirse al futuro; buscar la realización de los ideales de perfección captando las posibilidades máximas y concretas de realización en cada momento histórico. Desde Zubiri se puede argumentar a favor de la utopía, pero no del utopismo ignorante de las mediaciones reales y, por ello, ciego para comprender que existe una gran distancia entre los proyectos y su realización; distancia que, por lo demás, nunca podrá ser superada completamente. En este sentido, escribe Zubiri (1986: 582-583) lo siguiente:

"Nadie puede proyectar exhaustivamente la realidad que va a resultar de la realización de su proyecto, aun en el supuesto de que no se interpusiera ningún otro elemento. $Y$ esto porque la realización agrega inexorablemente el carácter de realidad a lo que no era sino proyecto. La realización del proyecto transciende constitutivamente del proyecto mismo; es más, pura y simplemente, por el hecho de ser realización. La realidad transciende del proyecto tanto porque el proyecto emerge de ella como porque es en ella donde se va a insertar el proyecto".

Para Ellacuría (1991: 369 y ss.), una filosofía de la historia a la altura de los tiempos debe partir de la posibilidad real de aniquilación. Si hasta el siglo XIX, el problema fundamental con el que se enfrentaba el ideal de progreso planteado por la filosofía de la historia era el de la posible finitud del Universo, las cosas cambiaron radicalmente a partir de mediados del siglo XX: por un lado, la ciencia fijará estos límites del universo en una amplitud tal que desborda toda previsión histórica; pero, por otro lado, la humanidad se hace consciente de la posibilidad de aniquilación de la vida a causa de la acción humana, ya sea de forma voluntaria o involuntaria. Esto hace que se plantee en términos de historia y filosofía de la historia lo que antes se planteaba en términos de naturaleza. La historia puede llegar a anular su propia base natural.

Por todo ello, hoy más que nunca, se requiere una consideración responsable de la realidad que la historia modifica y una vigilancia y previsión constante de los males que esa modificación puede conllevar a medio y largo plazo. Cada acción llevada a cabo por el ser humano, por pequeña que sea, supone una irreversible modificación del cosmos. En este sentido debe entenderse el concepto de "libertad comprometida" zubiriano: "La libertad no es una afuncionalidad, como si cada decisión libre flotara en el vacío de todas las decisiones. Esto no es verdad. En una o en otra medida, la libertad está siempre comprometida consigo misma" (Zubiri 1992: 145).

El ser humano, ciertamente, es autor de su vida en cuanto está abierto a la realidad y a su propia realización; pero también es actor. Por ello la vida no puede ser entendida como omnímodo proyecto: "No se puede escindir de un lado el proyecto y de otro la vida psicofísica. Al hombre no le basta con forjar un proyecto, tiene que realizarlo (...) poner en realización unas posibilidades es insertarlas para reconformarlas en el curso psicofísico" (Zubiri 1986: 582). 
Hemos de tener en cuenta que nuestra vida se realiza por la apropiación de las posibilidades proyectadas; la personalidad se va definiendo a partir de las de decisiones. Lo que vale también para la sociedad en su conjunto en la forma de apropiaciones colectivas. Los proyectos que realizamos nos abren múltiples posibilidades, pero también nos cierran otras que quizás sean esenciales para la realización de la especie. Soy actor de mi vida porque en mi proyección en la realidad, en su manejo y manipulación, mis proyectos revertirán sobre mí; seré lo que haga de mí, seremos lo que hagamos de nosotros. Soy el actor de mi vida, donde la apropiación que decidí como autor, se conforma como el "argumento de mi vida" como actor.

La praxis de raigambre zubirina parte de la constatación de nuestro carácter religado a una realidad que se impone, exigiendo respeto y compromiso. Esta exigencia crece cuanto estamos ante otras realidades personales; entonces el compromiso se transforma en justicia social.

La realidad humana es realidad moral, realidad que tiene que hacerse por apropiación de posibilidades. Esto convierte a los seres humanos en realidades dignas, merecedoras de las condiciones necesarias para el desarrollo de su propia moralidad, para su realización.

Zubiri ha afirmado que las ideas morales o ideales solo pueden ser justificados si son universalizables. El potencial para la crítica social de esta teoría es enorme. En este sentido, según Germán Marquínez (1995: 129), "posibilitar significa poner al ser humano (a todos los hombres) en condiciones de tener acceso a las posibilidades ya creadas y disponibles en una determinada sociedad; al menos a un mínimo de aquellas que son indispensables para una vida humanamente buena o digna".

La filosofía de Zubiri puede verse como un instrumento de crítica de una realidad insostenible política y moralmente donde miles de millones de personas se encuentran en una situación de miseria que impide la realización exigida por el mero hecho de ser realidades morales.

La exigencia de justicia social que se sigue de aquí ha sido uno de los puntos de partida de la teología de la liberación no solo de Ellacuría, sino también de otros como Jon Sobrino o Enrique Dussel. Estos autores, partiendo de la exigencia zubiriana de enfrentamiento con la realidad, han desarrollado esta premisa en una triple vertiente: hacerse cargo de la realidad, cargar con la realidad y encargarse de la realidad (Estrada 1998: 293-295). Consideramos, así, totalmente coherente la petición zubiriana de atenimiento a la realidad con la conclusión de Estrada (1998: 296) de que "el enfrentamiento con la realidad pasa por atender a los sujetos más deshumanizados y empobrecidos de nuestras sociedades y desde ahí hay que hacer la crítica a la sociedad y a la misma Iglesia, denunciando los encubrimientos y los compromisos legitimadores de la explotación del hombre por el hombre".

\section{De la realidad zubiriana a la realidad histórica en Ellacuría}

Si nos referimos concretamente a Ellacuría, este construye su filosofía de la liberación a partir del dinamismo de la realidad desarrollado por Zubiri. Tomará como referencia el curso impartido por su maestro en 1968 y publicado en 1989, Estructura dinámica de la realidad. Según la idea central de este curso, la realidad se ha constituido de acuerdo a una serie dinamismos que habrían ido produciéndose según el siguiente orden: causal, variación, alteración, mismidad, suidad y convivencia, que se desdobla, a su vez, en sociedad e historia.

La filosofía de la realidad histórica de Ellacuría pretende hacerse cargo de todos estos dinamismos, ya que solo partiendo de un análisis del dinamismo histórico que incorpore todos los demás dinamismos, se puede arribar a una verdadera "praxis histórica" en la que se creen capacidades y apropien posibilidades; y solo así se consigue plantear una praxis como "liberación personal", una praxis que se sabe obligadamente social y libre de toda mistificación (Ellacuría 1991: 470-472). En esta apretada oración aparecen varios elementos que han de ser explicados: 1) la contraposición entre mera filosofía de la historia y filosofía de la realidad histórica; 2) la forma en que esta filosofía histórica incorpora todos los dinamismos de la realidad; 3) la estrecha relación entre antropología y filosofía de la historia en Ellacuría.

Respecto al primer aspecto Ellacuría era consciente de la diferencia que hay entre una filosofía de la praxis de raíz zubiriana y la marxista, e interpreta esta diferencia a favor de Zubiri.

La filosofía de la praxis no puede consistir en una subordinación de lo filosófico a lo político, ya que tiene 
un trasfondo metafísico ineludible; la filosofía de la praxis es entrega a lo último de la realidad. Pero, por otro lado, tampoco es posible un cultivo en sí de la filosofía ajeno a la concreta situación socio-histórica. Ellacuría (1994: 78) no tenía dudas respecto de la relación que la filosofía de Zubiri guardaba con la situación concreta, aunque este no se hubiera prodigado en su explicitación: consiste "en hacer del filosofar un pensar efectivo desde la más concreta situación real sobre la realidad más total y concreta". Lo que para Ellacuría (1994: 76) supone lo siguiente:

"una implantación de intelección y praxis que supera la disyunción marxiana de contemplación y transformación, pues si es cierto que el mundo debe ser transformado no es ociosa la pregunta por el sentido de esa transformación. Naturalmente, esto implica que se piensa efectivamente desde una situación real y no es real si no es absolutamente concreta, pero para que la concreción no limite y ahogue el pensamiento es menester posibilitar el acceso a lo que es la totalidad de la realidad".

Ellacuría (1991: 447-454) enumera los dinamismos de los que ha de partir la filosofía de la realidad histórica: fuerzas naturales, biológicas, psíquicas, realizaciones humanas, relaciones humanas, ideologías y elementos personales. Todos ellos son momentos estructurales de la historia y, por lo tanto, elementos esenciales para una filosofía de la historia. El marxismo, en su desatención a la contemplación, ha minusvalorado especialmente los momentos natural y personal.

La atención al dinamismo natural permite ir más allá de la interpretación dialéctica del conflicto. El dinamismo humano porta el conflicto propio de los dinamismos que incorpora, incluido el animal, y precisamente por ello, la unidad de la especie no está dada perfectamente, sino cargada de conflictividad. Por lo demás, esta manera de entender el conflicto impide reducirlo explicativamente a momento necesario para una síntesis superior. El conflicto no es el ardid de una razón astuta. Por ello, el ser humano no puede esperar que la naturaleza o la dialéctica acaben con él. Dicho de otra forma, será responsable de su solución a través de una praxis social e histórica adecuada (Ellacuría 1991: 160-165).

Respecto al segundo aspecto, la manera en que la filosofía de la realidad histórica integra los dinamismos inferiores de la realidad, constituye uno de los momentos en que con más claridad Ellacuría se separa de su maestro. Efectivamente, Zubiri pensaba que la historia, como último dinamismo de la realidad, debía incorporar todos los demás; pero lo que nunca hizo fue convertir a la historia en el lugar de la filosofía por excelencia. Cosa que sí hace Ellacuría (1994: 65):

"Si no nos volvemos a lo que está haciéndose y a lo que está por hacer, se nos escapa la verdad de la realidad. Hay que hacer la verdad, lo cual no supone primariamente poner en ejecución, realizar lo que ya se sabe, sino hacer aquella realidad que, en juego de praxis y teoría, se muestra como verdadera. Que la realidad y la verdad han de hacerse y descubrirse, y que han de hacerse y descubrirse en la complejidad colectiva y sucesiva de la historia, de la humanidad, es indicar que la realidad histórica puede ser el objeto de la filosofía".

Ellacuría (1994: 52) partirá de la idea zubiriana de que el objeto de la filosofía es el todo de la realidad en su carácter físico, dinámico procesual y respectivo, "la realidad unitaria intramundana en un proceso hacia formas superiores de realidad". Por lo demás, de ello se sigue que tal objeto no es unitario solo conceptualmente, sino que la misma realidad intramundana constituye una unidad física, aun cuando compleja y diferenciada.

Este dinamismo se expresa en un "dar de sí" de la realidad que tiene sentido evolutivo, ya que "la realidad (...) es un proceso de realización en el que se van dando cada vez formas más altas de realidad, que retienen las anteriores, elevándolas" (Ellacuría 1994: 59); incluso retiene y eleva el dinamismo de la suidad, de la persona.

Hasta aquí, el acuerdo de Ellacuría con Zubiri es total. Pero el primero, insistimos, da un paso más: en cuanto que la realidad histórica es el último momento de este "dar de sí", se constituye como objeto último de la filosofía y la manifestación suprema de la realidad. El estudio de la historia es el estudio de la realidad entera "asumida en el seno social de la libertad" (Ellacuría 1994: 62), donde esta se actualiza en su momento más rico y abierto. Si queremos saber la realidad, la verdad de realidad, hemos de estudiar su dinamismo último, en el que se muestra lo que se está haciendo y lo que está por hacer.

Con ello, Ellacuría (1994: 111) (ㅇ). interpreta la filosofía de Zubiri como una filosofía de la praxis en sentido radical: 
"Por praxis entendemos aquí la totalidad del proceso social, en cuanto transformador de la realidad tanto natural como histórica. (...) La realidad histórica sería la realidad radical, desde el punto de vista intramundano, en la cual radican todas las demás realidades. (...) Esta realidad una es intrínsecamente dinámica. El dinamismo entero de la realidad histórica es lo que ha de entenderse como praxis".

Si la mayor realidad y la mayor verdad se descubren en el proceso histórico, entonces, el ser humano, sujeto de la historia, tiene que hacer en tal proceso aquella realidad que se muestra como verdadera: la realización de la Humanidad (모):

La filosofía es, en última instancia, reflexión sobre las posibilidades de realización de la especie humana en la historia, realización constituida como momento cumbre de la verdad y la realidad. La filosofía, como filosofía de la historia, se transforma en filosofía de la praxis: en "un pensar efectivo desde la más concreta situación real sobre la realidad más total y concreta" (Ellacuría 1994: 75), más allá de un presunto cultivo en sí que le hace huir del compromiso real y la constituye en un poder al servicio de los grupos dominantes. La filosofía no puede renunciar a las preguntas por el sentido de la totalidad y de la posibilidad de transformación de esta totalidad. La filosofía tiene que tener en cuenta una realidad dada, pero, al mismo tiempo, una realidad que hay que hacer por el rodeo de la posibilidad.

Por su capacidad de conjugar la realidad en su concreción y totalidad, la filosofía se muestra como el verdadero lugar de fusión de teoría y praxis. A través de ella descubrimos que la teoría no está contrapuesta a la praxis; más bien al contrario, constituye su momento de conciencia: la teoría, en su discernimiento sobre la praxis, es el momento totalizador, globalizador y dador de sentido. La teoría se presenta, así, como "ideología" en un sentido positivo, es decir, como constructora de representaciones de la praxis que le dan sentido e impulso desde la visión de la totalidad (Ellacuría 1994: 111-112).

En tercer y último lugar, la filosofía de la realidad histórica está estrechamente conectada con la antropología. Obviamente, de acuerdo con su idea de que el dinamismo histórico subsume el resto de dinamismos (incluido, por supuesto, el de la suidad), Ellacuría interpretó la antropología zubiriana en clave histórica. De esta forma, si Zubiri defendió que el ser humano está religado a la realidad, Ellacuría entenderá que, dado que la historia es la culminación del "dar de sí" de lo real, el hombre está religado a la historia.

Diego Gracia (1994: 351) observa que para Ellacuría "la historia es el lugar de la religación. Y en consecuencia también lo es de la 'obligación moral' (...) de realización de la ética". En la medida en que la historia se construye en el proceso de creación de posibilidades, es labor de la ética.

Entendemos ahora la triple vertiente del enfrentamiento con la realidad que destacaba más arriba Estrada: a causa del carácter ético de la realidad y de la historia, y en la medida en que está religado a ambas, el ser humano está obligado a hacerse cargo de la realidad, a encargarse de la realidad y a cargar con ella, y, en cuanto realidad culminante, a cargar y hacerse cargo de la historia. Como el sujeto de la historia es la especie humana, el imperativo lo tiene el ser humano "como miembro a la vez solitario y solidario de la especie humana. Las obligaciones morales del hombre, de cada hombre, se extienden al conjunto de la especie, y por consiguiente de la sociedad humana presente y futura" (Gracia 1994: 352).

En todo caso, hemos de insistir en que esta interpretación histórica de la ética no implica una recaída en la minusvaloración marxista del componente personal de la historia; bien al contrario, se trata de una reapropiación humanista de la historia; he aquí el quid de la teología de la liberación.

Ello conlleva dos importantes implicaciones. En primer lugar, la historia no es un proceso teleológico, sino que, de la misma forma que el ser humano singularmente considerado es una "realidad abierta" (Zubiri 1989: 208), el dinamismo histórico es incierto, abierto. A la inversa, también podemos decir que la apertura humana no es una "apertura contemplativa, sino necesariamente transformadora" (Ellacuría 1991: 439). En segundo lugar, la libertad no es solo un rasgo esencial del dinamismo personal, sino también del histórico. En este sentido, no se deja reducir a mera abstracción: es una libertad falaz aquella "que no se apoya en la posibilitación real de las condiciones de esa libertad: si se tiene poder para optar, pero no se puede optar, porque no se cuenta con posibilidades reales, se está negando la libertad humana, la libertad histórica" (Ellacuría 1991: 412). La verdadera libertad está en las antípodas de la libertad meramente formal de la ideología neoliberal. 


\section{Notas}

1. Gracia (1976 y 1994) Ilega a decir que algunos textos de Zubiri son más comprensibles desde las filosofías de Feuerbach y Marx que desde Aristóteles u otros autores clásicos, en cuanto que en ellos ya se encontraba incipientemente la superación de la escisión entre sentir e inteligir, paso necesario para una verdadera filosofía de la acción. Por ello, la "aprehensión primordial de realidad" supone la culminación de la visión marxista de la "actividad sensorial humana" como praxis.

2. "La filosofía primera es una filosofía de la praxis, una praxeología". González considera, además, que otro rasgo esencial de la praxeología zubiriana en su carácter de filosofía primera. Insistiremos en ella más adelante; ahora es suficiente con subrayar su distancia del marxismo: frente a la explicación metafísica o seudocientífica del marxismo, en Zubiri puede rastrearse el análisis radical de la praxis. "La praxeología difiere de las filosofías marxistas de la praxis, al menos en la medida en que estas se formularon para subrayar los aspectos 'subjetivos' de los procesos históricos, destacando la importancia de la intervención activa de los individuos y de los grupos humanos sobre el mundo natural y social con vistas a transformarlo. Tales enfoques de la praxis humana desbordan los límites de la praxeología y se adentran en el campo de las teorías científicas (o metafísicas) sobre la historia. La praxeología no decide la cuestión sobre si en la historia los factores 'objetivos' o los factores 'subjetivos' son determinantes en última instancia. Ello no obsta para que la praxeología pueda hacer suyas muchas de las afirmaciones de Karl Marx sobre la praxis, reinterpretándolas desde una perspectiva propia" (González 1997: 189).

3. No en vano, Manuel Sacristán (1984: 414-416) ha dicho que para la filosofía de la praxis gramsciniana el problema fundamental de la filosofía es la antropología. Entendiendo aquí la pregunta antropológica no como la cuestión sobre la naturaleza biológica del hombre, sino por su realidad final: “¿Qué puede llegar a ser el hombre?"; por la posibilidad de que pueda llegar a dominar su destino. A su vez, Sacristán afirma que tal antropología -para evitar el fracaso del interrogante- debe superar la concepción individualista y solipsista del hombre. Solo entendiendo adecuadamente que la noción que la noción de individuo humano hace referencia intrínsecamente a los otros y a la naturaleza, puede responderse adecuadamente a la pregunta. El hombre es relación orgánica a los otros y relación activa a la naturaleza.

4. Antonio Pintor (1996: 51) ha considerado la importancia de matizar esta afirmación, en tanto que la fenomenología constituye "un amplio movimiento de límites muy imprecisos en el que caben filósofos muy heterogéneos". Más bien hay que entenderla como una "actitud", un "instrumento": "'Fenomenología', por tanto, significa aquí la irrupción de un nivel descriptivo que sirve como instrumento del análisis filosófico, pero no se identifica en cuanto tal con ninguna posición teórica" (Pintor 1996: 80). El mismo Zubiri (1935: 19) atisbó ya estas potencialidades de la fenomenología al distinguir "entre lo que es una filosofía fenomenológica y el modo como ella ha encarnado efectivamente en Husserl". Más allá de su concreta forma husserliana, la fenomenología constituye una nueva "idea de filosofía" (Zubiri 1935: 10).

5. Hay, entonces, dos nociones de fundamento en Zubiri: por un lado, los esbozos racionales buscan la realidad como fundamento de lo dado en aprehensión; pero, por otro lado, lo dado en la aprehensión es fundamento de todo esbozar racional (Cerezo 1998: 277).

6. Esto no quiere decir que tal distinción no estuviera presente en Zubiri en sus escritos anteriores. Ya desde su Memoria de Licenciatura de 1921, Zubiri (1999: 25) tuvo presente la distinción entre explicación y descripción; y el capítulo primero de su tesis de 1923 está dedicado a aclarar la distinción entre el método descriptivo y el explicativo (Zubiri 1999: 117-131).

7. Aunque en la llustración la filosofía de la historia estuvo interesada en la liberación de la humanidad -en la autoliberación bajo la consideración de que el sujeto de la historia era la misma humanidad-, la experiencia histórica negativa condujo a la desconfianza en la capacidad de autoliberación y, consecuentemente, llevó a las figuras más importantes de la llustración a crear un macrosujeto director de la historia que asegurara tal liberación. Desde entonces pareció que la historia tenía su propia lógica y un fin ya configurado: el proyectado por Europa. Precisamente, lo que mueve a la filosofía de la liberación que parte de Zubiri es el intento de recuperar el interés emancipador que movió la llustración, 
pero superando este macro-sujeto y esta teleología; superando el desarrollismo para recuperar el papel de la actuación, de la praxis humana en la construcción histórica siempre abierta (González 1993: 110-114).

8. Como ha observado Héctor Samour (1994: 19), la propia metafísica se transforma en un apartado de la filosofía de la praxis: "la praxis queda caracterizada con una densidad enorme, por cuanto en ella no solo está en juego el destino de la humanidad y de los diversos grupos humanos, e incluso el de la historia misma, sino más radicalmente, la realización misma de la realidad en tanto que realidad, es decir, su constitución trascendental".

9. Consideramos que esta tesis de realización de la humanidad, aunque no se halla explícitamente afirmada en los textos zubirianos, es consecuente con sus planteamientos. Corominas (2000: 172), en cambio, considera que esta tesis separa a Ellacuría de Zubiri porque supone una vuelta a cierto teleologismo, a una dependencia en sentido marxista de la ética con respecto a la filosofía de la historia que "pretende hallar en ella un fin y un para qué del hacer moral". Pensamos que se puede mantener la noción de humanización histórica considerándola un "ideal" irrenunciable y no como una consecuencia necesaria del proceso histórico. Otra cosa es que Ellacuría, desde este planteamiento zubiriano, se abra, posiblemente, a la perspectiva marxista. En todo caso, Corominas (2000: 173) reconoce, en línea con lo que venimos diciendo en este trabajo, que hay algo que diferencia radicalmente el planteamiento de Zubiri-Ellacuría del de Hegel-Marx: "Ellacuría considera que la ventaja de la conceptuación zubiriana de la historia, frente a la de Hegel y la de Marx, es que, en Zubiri, 'el carácter absoluto de la historia no está en la absolutización de la historia, sino en ser ella el lugar de absolutización de las personas'. Como en Marx y en Hegel, la historia sería también un proceso de absolutización, pero, en lugar de ir hacia el Espíritu Absoluto y de ser un proceso que los individuos padecen más que hacen, va a capacitar las personas en orden a ser absolutas".

\section{Bibliografía}

Cerezo, Pedro

1998 "Idea y ámbito de la metafísica en Ortega y Zubiri", en Jorge. J. E. Gracia (coord.), Enciclopedia Iberoamericana de Filosofía, vol. XVII. Madrid, Trotta/CSIC.

Conill, Jesús

1988 El crepúsculo de la metafísica. Barcelona, Anthropos.

Corominas, Jordi

1993 "Fundamentos de una ética liberadora", en Voluntad de vida. Managua, Seminario ZubiriEllacuría/UCA: 47-66.

2000 Ética primera. Aportación de X. Zubiri al debate ético contemporáneo. Bilbao, Desclée de Brouwer.

Corominas, Jordi (y Joan Albert Vicens)

2006 Xavier Zubiri. La soledad sonora. Madrid, Taurus.

Cortina, Adela

1996 "Éticas del deber y éticas de la felicidad”, en Ética y Estética en Xavier Zubiri. Madrid, Trotta: 49-62.

Ellacuría, Ignacio

1991 Filosofía de la realidad histórica. Madrid, Trotta.

1994 El compromiso político de la filosofía en América Latina. Santafé de Bogotá, El Búho.

\section{Estrada, Juan Antonio}

1990 La teoría crítica de Max Horkheimer. Granada, Editorial Universidad de Granada.

1998 "La influencia de la filosofía en la teología de la liberación", Proyección. Teología y mundo actual (Granada), n 45: 285-296.

2004 Por una ética sin teología. Habermas como filósofo de la religión. Madrid, Trotta. 
735-752.

González, Antonio

1997 Estructuras de la praxis. Madrid, Trotta.

Gracia, Diego

1976 "Materia y sensibilidad", en Realitas, vol. II. Madrid, Sociedad de Estudios y Publicaciones/Labor: 203-243.

1986 Voluntad de verdad. Barcelona, Labor.

1994 "Filosofía práctica”, en José Antonio Gimbernat y Carlos Gómez (coord.), La pasión por la libertad. Homenaje a Ignacio Ellacuría. Estella, Verbo Divino: 329-352.

Gramsci, Antonio

1953 Introducción a la filosofía de la praxis. Barcelona, Península, 1972.

Hogue, William

2018 "The Ideal of a Radical Christian Intellectual”, Religions (Nueva York), nº 277.

Hortal, Augusto

1996 "El realismo moral”, en Ética y estética en Xavier Zubiri. Madrid, Trotta: 71-79.

López Aranguren, José Luis

1958 Ética, Madrid, Alianza, 1990.

Marquínez, Germán

1995 Realidad y posibilidad. Santafé de Bogotá, Magisterio.

Pintor, Antonio

1994 Realidad y verdad. Salamanca, Universidad Pontificia de Salamanca.

1996 Génesis y formación de la filosofía zubiriana. Salamanca, Universidad Pontificia.

Sacristán, Manuel

1984 Papeles de filosofía. Panfletos y materiales II. Barcelona, Icaria.

Samour, Héctor

1994 "Introducción a la filosofía de la liberación de Ignacio Ellacuría", en El compromiso político de la filosofía en América Latina. Santafé de Bogotá, El Búho.

Schweitzer, Don

2018 "The role of human response in the resurrection of jesus christ", Toronto Journal of Theology, $\mathrm{n}^{\circ} 34$ :

63-77.

Zubiri, Xavier

1935 "Filosofía y metafísica", Cruz y Raya, n 30: 7-60.

1980 Inteligencia sentiente. Inteligencia y realidad. Madrid, Alianza.

1983 Inteligencia y razón. Madrid, Alianza.

1986 Sobre el hombre. Madrid, Alianza.

1989 Estructura dinámica de la realidad. Madrid, Alianza.

1992 Sobre el sentimiento y la volición. Madrid, Alianza.

1999 Primeros escritos (1921-1926). Madrid, Alianza. 